\title{
Barbiturates and serum calcium in the elderly
}

\author{
R. E. YounG \\ M.B., Ch.B. \\ L. E. RAMSAY \\ M.B., M.R.C.P. \\ T. S. MURRAY* \\ M.B., M.R.C.P. \\ Department of Medicine, Western Infirmary, and \\ *Department of General Practice, Woodside Health Centre, Glasgow G11 6NT
}

\section{Summary}

In a retrospective study, based on a biochemical survey of people aged 65 and over in a general practice, subjects taking a barbiturate preparation for indications other than epilepsy had a significantly lower serum calcium concentration than did those taking nitrazepam or diazepam. Ordinary doses of barbiturate may adversely affect vitamin $D$ metabolism in the elderly.

\section{Introduction}

There have been several reports of altered vitamin D metabolism and osteomalacia in epileptics treated with anticonvulsants, including phenobarbital (Dent et al., 1970; Hahn et al., 1972; Kruse, 1968; Richens and Rowe, 1970). These drugs appear to influence vitamin $\mathbf{D}$ metabolism by inducing hepatic microsomal enzymes (Dent et al., 1970; Richens and Rowe, 1970). Use of barbiturates was recently implicated in the osteodystrophy complicating long-term haemodialysis and renal transplantation (Pierides et al., 1976). One of the authors (L.E.R.) had formed a clinical impression that low serum calcium and elevated alkaline phosphatase values were unduly frequent in elderly patients receiving barbiturates, often at ordinary hypnotic doses. Others had suggested that the combination of nutritional deficiency of vitamin D and barbiturate habituation may cause more morbidity in the elderly than is generally recognized (Fraser, Thompson and Khan, 1976). For these reasons the authors undertook the retrospective study described below, seeking evidence that barbiturate treatment in the elderly for indications other than epilepsy may adversely affect vitamin D metabolism.

\section{Methods}

\section{Population studied}

The basis for the study was a laboratory screening

Correspondence : Dr R. E. Young, Department of Medicine, Gardiner Institute, Western Infirmary, Glasgow G11 6NT. survey aimed at all people aged 65 years and over in a semi-urban general practice. The survey was conducted between April 1973 and March 1974 and included 403 subjects, representing $82 \%$ of those eligible judged from the practice revised age/sex register. Details of the population studied and of the methods of contacting subjects, obtaining samples and laboratory analysis are presented elsewhere (Murray and Young, 1977). For the authors' purpose, the information available on each subject was age, sex, any major illness, current drug therapy and results of a biochemical screen which included measurement of serum calcium, phosphate, alkaline phosphatase, albumin and creatinine. The information on drug therapy had been obtained from the practice records and by questioning the subjects at the time of the survey. In drawing up the three subgroups described below, it was predetermined that subjects known to have any bone disease before the survey would be excluded.

\section{Barbiturate group}

Twenty-four subjects $(6 \%$ of those screened) were taking a barbiturate. Two subjects with missing biochemical data and one with Paget's disease of bone were excluded, leaving twenty-one subjects for analysis. One had a history of partial gastrectomy. The dose and duration of treatment with barbiturates were unknown, but barbiturate had not been prescribed as an anticonvulsant in any subject.

\section{Nitrazepam/diazepam group}

Subjects taking nitrazepam or diazepam were chosen to form a control group because the indications for the use of these drugs (hypnotic and tranquillizer) are often similar to those for barbiturates and because they do not induce hepatic microsomal enzymes (Whitefield et al., 1973). Substitution of these drugs allows healing of drug-induced osteomalacia (Greenwood, Prunty and Silver, 1973). Of thirty-nine subjects, twelve were receiving nitrazepam, twenty-five diazepam, and two both drugs. 
TABLE 1. Comparison of results for the three groups (mean \pm s.d.)

\begin{tabular}{|c|c|c|c|c|c|c|c|c|c|}
\hline & \multirow{2}{*}{$\underset{\text { Barbiturate }}{\text { A }}$} & \multirow[b]{2}{*}{$(n)$} & \multirow{2}{*}{$\begin{array}{c}\text { B } \\
\text { Nitrazepam/ } \\
\text { diazepam }\end{array}$} & \multirow[b]{2}{*}{$(n)$} & \multirow{2}{*}{$\begin{array}{c}\mathrm{C} \\
\text { No barbiturate, } \\
\text { nitrazepam or } \\
\text { diazepam }\end{array}$} & \multirow[b]{2}{*}{$(n)$} & \multicolumn{3}{|c|}{$P$ values* } \\
\hline & & & & & & & $\mathrm{A} v . \mathrm{B}$ & $\mathrm{A} v . \mathrm{C}$ & B v. C \\
\hline Number of subjects & 21 & & 33 & & 30 & & - & - & - \\
\hline Age & $72 \cdot 3 \pm 4 \cdot 4$ & & $70 \cdot 2 \pm 5 \cdot 1$ & & $71 \cdot 7 \pm 5 \cdot 5$ & & NS & NS & NS \\
\hline Female : male & $1 \cdot 33: 1$ & & $5 \cdot 60: 1$ & & $2 \cdot 75: 1$ & & $<0.1$ & NS & NS \\
\hline Creatinine $(\mu \mathrm{mol} / \mathrm{l})$ & $89 \cdot 2 \pm 20 \cdot 8$ & $(20)$ & $88 \cdot 6 \pm 23 \cdot 7$ & (31) & $94 \cdot 8 \pm 24 \cdot 6$ & (30) & NS & NS & NS \\
\hline Albumin $(\mathrm{g} / \mathrm{l})$ & $45 \cdot 1 \pm 0 \cdot 48$ & (21) & $44 \cdot 2 \pm 0.58$ & (33) & $44 \cdot 2 \pm 0.46$ & (28) & NS & NS & NS \\
\hline Calcium (mmol/l) & $2 \cdot 28 \pm 0 \cdot 11$ & (21) & $2 \cdot 38 \pm 0 \cdot 13$ & (31) & $2 \cdot 35 \pm 0 \cdot 13$ & (28) & $<0.01$ & $<0.05$ & NS \\
\hline Corrected calcium & $2 \cdot 15 \pm 0.09$ & (21) & $2 \cdot 28 \pm 0 \cdot 14$ & (31) & $2 \cdot 25 \pm 0 \cdot 14$ & (28) & $<0.001$ & $<0.01$ & NS \\
\hline Phosphate $(\mathrm{mmol} / \mathrm{l})$ & $1 \cdot 01 \pm 0.18$ & (21) & $1.07 \pm 0.17$ & (31) & $1.08 \pm 0.20$ & (30) & NS & NS & NS \\
\hline Alkaline phosphatase (KAu) & $8 \cdot 69 \pm 4 \cdot 56$ & (21) & $8 \cdot 06 \pm 3 \cdot 13$ & (32) & $8 \cdot 16 \pm 3 \cdot 81$ & (30) & NS & NS & NS \\
\hline Elevated alkaline phosphatase & $6(29 \%)$ & & $5(16 \%)$ & & $6(20 \%)$ & & NS & NS & NS \\
\hline Receiving diuretic & $9(43 \%)$ & & $11(33 \%)$ & & $6(20 \%)$ & & NS & NS & NS \\
\hline
\end{tabular}

$* \mathrm{NS}=P>0 \cdot 1$.

TABLE 2. Further analysis of corrected serum calcium concentration in the barbiturate and nitrazepam/diazepam groups (mean \pm s.d., $\mathrm{mmol} / \mathrm{l}$ )

\begin{tabular}{lccccc}
\hline & Barbiturate & $(n)$ & $\begin{array}{c}\text { Nitrazepam/ } \\
\text { diazepam }\end{array}$ & $(n)$ & $P$ \\
\hline Females & $2 \cdot 17 \pm 0 \cdot 10$ & $(12)$ & $2 \cdot 27 \pm 0.14$ & $(26)$ & $<0.025$ \\
Males & $2 \cdot 13 \pm 0.09$ & $(9)$ & $2 \cdot 31 \pm 0.15$ & $(5)$ & $<0.02$ \\
Aged 70 years + & $2 \cdot 15 \pm 0.10$ & $(16)$ & $2 \cdot 24 \pm 0.14$ & $(15)$ & $<0.05$ \\
& $($ mean age 73.9 & years $)$ & $($ mean age 74.6 & years $)$ & \\
Diuretic & $2 \cdot 15 \pm 0 \cdot 10$ & $(9)$ & $2 \cdot 28 \pm 0.13$ & $(11)$ & $<0.02$ \\
No diuretic & $2 \cdot 16 \pm 0.09$ & $(12)$ & $2 \cdot 28 \pm 0.15$ & $(20)$ & $<0.025$ \\
\hline
\end{tabular}

Five patients also receiving a barbiturate, and one with skeletal metastases from breast carcinoma were excluded, leaving thirty-three subjects for analysis.

\section{Group not receiving barbiturate, nitrazepam or diazepam}

This group was studied to explore further the differences observed between the barbiturate and nitrazepam/diazepam groups. A sample of thirty subjects not receiving any of these drugs was obtained using random numbers. Four subjects without biochemical data and one with skeletal metastases from bronchogenic carcinoma were excluded before the total of thirty subjects was obtained.

\section{Laboratory and statistical methods}

Serum calcium, phosphate, alkaline phosphatase, albumin and creatinine were measured by routine methods as part of a Technicon Autoanalyser 12/60 screen. Serum calcium concentration was corrected to an albumin concentration of $40 \mathrm{~g} / \mathrm{l}$ (Payne et al., 1973). The statistical methods used were the Student's $t$-test and $\chi^{2}$ with Yates' correction. Alkaline phosphatase concentration was log transformed for analysis to normalize the distribution of the observations.

\section{Results}

The results in the three groups are shown in Table 1. In the initial comparison of the barbiturate group with the nitrazepam/diazepam group, subjects taking barbiturates had a lower serum calcium $(P<0.01)$ and corrected calcium concentration $(P<0.001)$. The barbiturate group had slightly lower phosphate and slightly higher alkaline phosphatase values, but these differences were not significant. Using strict upper limits of normal for alkaline phosphatase (10 KAu for females, $12 \mathrm{KAu}$ for males) (Richens and Rowe, 1970), $29 \%$ of barbiturate-treated subjects $v .16 \%$ in the nitrazepam/ diazepam group had elevated levels, but again, the difference did not approach significance. The two groups matched well as regards serum creatinine and serum albumin. Barbiturate-treated subjects were slightly older and more of them were receiving a diuretic; the difference in sex ratio between the two groups approached significance $(P<0 \cdot 1)$. Further analysis was performed within these two groups to determine whether these factors could explain the significant difference in serum calcium (Table 2). Compared to the nitrazepam/diazepam group, corrected calcium concentration was significantly lower in barbiturate-treated females $(P<0.025)$ or males $(P<0.02)$. There was a weak, non-significant negative correlation between age and corrected calcium $(r=-0 \cdot 20, P>0 \cdot 1, n=52)$. Comparison restricted to subjects aged 70 years and over yielded groups closely matched for age, and corrected calcium was again significantly lower in the barbiturate group $(P<0.05)$. Finally, the corrected calcium 
concentration was lower in barbiturate-treated subjects whether or not they were receiving a diuretic.

The results of the analysis at this stage were open to two interpretations: that barbiturate treatment was associated with reduced serum calcium concentration, or that nitrazepam/diazepam use was associated with elevated serum calcium. The third group, subjects not taking barbiturate, nitrazepam or diazepam, was examined to distinguish between these possibilities. This group proved to be in all respects similar to the nitrazepam/diazepam group (Table 1). When compared with the third group, barbiturate treatment was again associated with low serum calcium $(P<0.05)$ and corrected calcium concentration $(P<0 \cdot 01)$.

\section{Discussion}

In retrospective studies it is difficult to be sure that apparent associations have not resulted from bias, or from the presence of confounding factors. The authors cannot find any source of bias in the conduct of the survey on which this study is based, and they carefully avoided bias when obtaining the groups for comparison. Regarding confounding factors, the differences in serum calcium were not attributable to age, sex or to the use of other drugs. Since the indications for prescription of barbiturates and nitrazepam/diazepam are similar but not identical, it is possible that the two groups were not matched for factors of which the authors have no knowledge. Considering those conditions commonly associated with low serum calcium, impaired renal function in the barbiturate group can be excluded by the results for serum creatinine. Only one subject had a history of gastric surgery, and there were no cases of clinically overt malabsorption or cholestasis. There seems no reason why barbiturates should be prescribed particularly for those with nutritional deficiency of vitamin $\mathrm{D}$, and consideration of the results for serum albumin does not suggest general nutritional deficiency in the barbiturate group. None of the subjects taking barbiturates was receiving in addition other drugs known to induce hepatic microsomal enzymes (Hunter, 1974). Within the limitations of this type of study it is therefore concluded that there was a true association of barbiturate treatment in the elderly with reduced serum calcium concentration. This is not evidence for cause and effect, but taken with the known influence of barbiturates on vitamin D metabolism in other circumstances (Dent et al., 1970; Hahn et al., 1972; Kruse, 1968; Pierides et al., 1976; Richens and Rowe, 1970), it seems reasonable to suggest that barbiturates were responsible for the reduction in serum calcium.

The clinical significance of the reduced serum calcium cannot be assessed from the present study and, in particular, the authors do not know whether it means that a number of these patients had osteomalacia. In the original survey the decision whether to investigate any biochemical abnormality was left to the individual doctors in the practice. As a result of the survey one of twenty-four patients receiving barbiturates was found to have radiological osteomalacia (presumed nutritional), while three of 378 subjects not receiving bariburates had osteomalacia diagnosed. Although the numbers are too small to be significant it is notable that the barbiturate patient in whom osteomalacia was diagnosed had a corrected serum calcium of $2.23 \mathrm{mmol} / 1$, while fourteen subjects in the barbiturate group had values lower than this. Since hypocalcaemia may be the only biochemical abnormality in osteomalacia (Stanbury, 1972) it is quite possible that further cases went undiagnosed in the barbiturate group. On the other hand the reduction in serum calcium may be a trivial biochemical abnormality, and further study will be required to determine its significance.

Comparing these findings with those in epileptics treated with anticonvulsants (Richens and Rowe, 1970) the reduction in serum calcium in the barbiturate group was of the same magnitude as that observed with anticonvulsants, and serum phosphate was unaltered in both studies. However, the results for serum alkaline phosphatase differed in the two studies. Epileptics treated with anticonvulsants had alkaline phosphatase values significantly higher than a control group, a difference not observed with barbiturates in the present study. The prevalence of elevated alkaline phosphatase levels using the same criteria was identical in patients treated with anticonvulsants and in those treated with barbiturates in the present study, but the findings in the control groups show that the criteria are too strict in the age range studied. In epileptics, elevated alkaline phosphatase was most frequently due to an increase in the liver isoenzyme, the bone fraction rising particularly in young patients aged 16-25 years (Richens and Rowe, 1970). The authors speculate that higher doses of barbiturate or combination with other anticonvulsants may be required to elevate the alkaline phosphatase, or that the alkaline phosphatase response may be modified in older patients.

Although the authors do not know the dose and duration of barbiturate treatment in their subjects, the drugs were not being prescribed as anticonvulsants, and in thirteen of the twenty-one subjects, the barbiturate was used as a hypnotic. It is probable that the reduction in serum calcium was associated with use of barbiturate at low or moderate dosage. The mechanism for altered vitamin $\mathrm{D}$ metabolism due to anticonvulsant drugs is not entirely clear (Christiansen et al., 1975; Stanbury, 1972) but it seems related to induction of hepatic microsomal 
enzymes (Dent et al., 1970; Richens and Rowe, 1970). Since it has been shown that barbiturates can cause enzyme induction when given in doses commonly used for hypnotic purposes (Whitefield et al., 1973), adverse effects of these ordinary doses on vitamin D metabolism would not be surprising, and may not be restricted to the elderly.

It is concluded that barbiturate treatment in the elderly, even at conventional non-anticonvulsant dosage, may influence vitamin $\mathbf{D}$ metabolism adversely. Clinicians should be alert to the possibility of osteomalacia in such patients. The conclusion from the present study will require to be tested prospectively and younger age groups should also be examined. The authors believe that their findings provide yet another reason why barbiturates should be reserved for those few indications where their use is essential.

\section{Acknowledgments}

We wish to thank the members of the practice team and the laboratory staff who helped with the screening project; Dr M. Bell, Dr. E. U. Buchanan, Dr J. Buchanan, Mr A. Crooks, Dr A. S. Harper, Mrs McDougall, Mrs Reilly, Dr J. T. Robson, Mrs Speirs, Dr P. D. Stewart and Sister Watt. We are grateful for the helpful comments of those who read the manuscript. R.Y. is funded by Nuffield Provincial Hospitals Trust.

\section{References}

Christiansen, C., Rodbro, P., Munck, O. \& Munck, O. (1975) Actions of vitamins $D_{2}$ and $D_{3}$ and $25-\mathrm{OHD}_{3}$ in anticonvulsant osteomalacia. British Medical Journal, 2, 363.

Dent, C.E., Richens, A., Rowe, D.J.F. \& Stamp, T.C.B. (1970) Osteomalacia with long term anticonvulsant therapy in epilepsy. British Medical Journal, 4, 69.

Fraser, H.S., Thompson, D. \& Khan, C. (1976) Clinical application of antipyrine half-life in saliva in a patient with osteomalacia. British Medical Journal, 1, 1507.

Greenwood, R.G., Prunty, F.T.G. \& Silver, J. (1973) Osteomalacia after prolonged glutethimide administration. British Medical Journal, 1, 643.

Hahn, T.J., Hendin, B.A., Scharp, C.R. \& Haddad, J.G. (1972) Effect of chronic anticonvulsant therapy on serum 25-hydroxycalciferol levels in adults. New England Journal of Medicine, 287, 900.

HUNTER, J. (1974) Enzyme induction and medical treatment. Journal of the Royal Collage of Physicians, London, 8, 163.

KRUSE, R. (1968) Osteopathien bei antiepileptischer Langzeittherapie. Monatsschrift für Kinderheilkunde, 116, 378.

MURRAY, T.S. \& YouNG, R.E. (1976) Laboratory survey in a geriatric population. Update, 14(1), 191.

Payne, R.B., Little, A.J., Williams, R.B. \& Milner, J.R. (1973) Interpretation of serum calcium in patients with abnormal serum proteins. British Medical Journal, 4, 643.

Pierides, A.M., Ellis, H.A., WARD, M., Simpson, W., Peart, K.M., Alvarez-Ude, F., Uldall, P.R. \& Kerr, D.N.S. (1976) Barbiturate and anticonvulsant treatment in relation to osteomalacia with renal haemodialysis and renal transplantation. British Medical Journal, 1, 190.

Richens, A. \& Rowe, D.J.F. (1970) Disturbance of calcium metabolism by anticonvulsant drugs. British Medical Journal, 4, 73.

Stanbury, S.W. (1972) Osteomalacia. Clinics in Endocrinology and Metabolism, 1, 239.

Whitefield, J.B., Moss, D.W., Neale, G., Orme, M. \& BRECKENRIDGE, A. (1973) Changes in plasma $\gamma$-glutamyl transpeptidase activity associated with alteration in drug metabolism in man. British Medical Journal, 1, 316. 